\title{
Emergency Services Efficiency at a Tertiary Care Hospital
}

\author{
Samina Waseem, ${ }^{1}$ Noreen Kousar, ${ }^{2}$ Muhammad Anwar ${ }^{1}$
}

\begin{abstract}
Background: An emergency department is a medical treatment facility which is specialized emergency medicine, the acute care of patients who present without any prior appointment either by their own means or by that of an ambulance.

Objective: To determine the efficiency of emergency services in a tertiary care hospital.

Methodology: It was a cross sectional study, conducted at Emergency Department of Sheikh Zayed Medical College/Hospital, Rahim Yar Khan, from August to October, 2019. A total of 139 subjects who were patients attending emergency department were involved in the study by using random sampling technique. Data was collected by a predesigned proforma. Variables included were age, sex, occupation, door to treatment time, presenting complaints of patient, designation of health care provider, further investigation advised, given treatment, referral to OPD or ward.

Results: Mean age of patients was $33 \pm 19$ years. Out of 139 patients, 59.7\% were males and from urban area each, $44.6 \%$ were illiterate, $75 \%$ of the study subjects were treated by a doctor, and $25.9 \%$ came with GIT complaints. It was noted that $48.2 \%$ of the patients had the first contact within 4 minutes, and treatment of $49.7 \%$ patients was started within 10 minutes, and $3.5 \%$ of the patients it took more than 25 minutes.

Conclusion: This study showed that almost half of the patients received treatment within four minutes while few of the patients have to wait for upto twenty five minutes to get healthcare, which is quite a long time as for as emergency healthcare services is concerned., additionally only half of the patients were received by doctors.

Key words: Emergency services, Door to treatment time, Healthcare providers.

Article Citation: Waseem S, Kousar N, Anwar M. Emergency Services Efficiency at a Tertiary Care Hospital. JSZMC 2020;11(2):24-28. DOI: https://doi.org/10.47883/jszmc.v11i2.6
\end{abstract}

\section{Introduction}

Treatment facility is specialized in emergency medicine, known as emergency department that provides acute care of patients, who presented there without prior appointment, reached there by their own means or by that of an ambulance. This emergency department is normally found at each tertiary, secondary or primary health care centers. ${ }^{1}$ It was estimated in a report by that 3.5 million people die every year because of respiratory tract infections. Injuries that have been counted each year due to vehicular or other accidents are about 10-15 million. There is estimated one death every 50 seconds and one get injured every 2 seconds. By this report we can feet that how much important are emergency services in every hospital. ${ }^{1,2}$

These are not only emergency services but they are organizations, which ensure the public safety and health by addressing and dealing with different emergencies. ${ }^{3}$ Some of them are dealing with specific emergencies, while others are dealing as a part of their normal responsibilities.
Many of these emergency departments are also engage in community awareness and prevention programs. Availability of emergency services depends mainly on location but in some cases also on the payments or insurance by recipients of these services. ${ }^{2}$ One of the most important pillar of each hospital is its Accident and Emergency department. Throughout the globe, these Emergency departments are serving and delivering every type and level of health care to a large number of patients with different complaints. As in emergency departments there is huge flow of un-planned nature of patients so the emergency department is responsible to provide initial treatment towards a broad-spectrum illnesses and injuries, some of which may be life threatening and require immediate attention. Patients which have no access to medical care in some of the countries, this emergency department are important entry point for seeking medical care. Almost each hospital operate their emergency 24 hours a day, although management and staffing could be varied according to patient volume. ${ }^{3,4,5}$

The efficacy of emergency services can be assessed

1. Department of Community Medicine, Sheikh Zayed Medical College, Rahim Yar Khan, Pakistan.

2. Department of General Surgery, Sheikh Zayed Medical College/Hospital, Rahim Yar Khan, Pakistan.

Correspondence: Samina Waseem, Assistant Professor, Department of Community Medicine, Sheikh Zayed Medical College, Rahim Yar Khan, Pakistan. 
by doing bench marking, response time. Response time usually is the amount of time that it takes for emergency responders to arrive at the scene of an incident, after that the emergency response system was activated. Efficient response time is a crucial component of emergency service system. ${ }^{6,7}$ Overcrowding is very concerned matter in emergency departments that can leads to inadequate patient care, which results in poorer patient outcome. To manage this issue, management should adopt escalation policies when they have to respond an increase in demand. These policies should aim to maintain their ability of delivering adequate care, without compromising Patient's safety, just by improving or modifying their normal practices. ${ }^{8,9}$ There are several indicators which we can use to assess and evaluate the efficiency of our emergency services like number of mortalities, door to treatment time, type of healthcare provider, readmission in less than 30 days, length of stay, and patient satisfaction. ${ }^{10,11}$

Most importantly, the time patient have to wait in emergency department has serious impact at all of these indicators. Literature review depicts the reasoning that treatment outcome for any disease or injury is time-sensitive, sooner we will provide treatment, better will be the outcome. ${ }^{10}$ It has also been noticed that almost $50 \%$ of emergency visits are of non-emergency type. ${ }^{8}$ This huge burden of patients who presented with variable complaints dictates the necessity of distribution of patients according to their symptoms severity. ${ }^{5}$ The purpose of conducting this study was to identify the current emergency timing patterns of the patients and the time spent in accident and emergency department, additionally, pattern of disease among patients attending the emergency department was also assessed. So the main objective of this study was to determine the efficiency of emergency services in Sheikh Zayed Medical College/Hospital, Rahim Yar Khan.

\section{Methodology}

This cross sectional study was conducted at Sheikh Zayed Medical College/Hospital, Rahim yar khan, Emergency Department from $1^{\text {st }}$ August to October, 2019. A total of 139 patients, were selected through random sampling technique, were observed silently and followed throughout their stay in emergency department, and after they received healthcare, data was collected and noted on a proforma. Inclusion Criteria: Patients included in the study, were those entering at the time of data collection and were willing to answer the questions. Patients who were unconscious were excluded. Variables included were; age, occupation and presenting complaints, time of first contact with doctor/health care provider, designation of health care provider, time taken to start treatment, first-aid given to patient, further investigation advised, provisional diagnosis, treatment, time of admittance, referral to OPD/ward and exit from emergency department.

Efficiency of emergency services was assessed by taking into consideration the door to $1^{\text {st }}$ contact time, door to treatment time and door to exit time. Ethical approval was sought from Institutional Review Board. Variables like age, to $1^{\text {st }}$ contact time, door to treatment time and door to exit time was presented as mean plus standard deviation and also as frequency and percentage, occupation and presenting complaints, designation of health care provider, and provisional diagnosis was presented as frequency and percentage. Data was entered and analyzed through SPSS version 20.

\section{Results}

A total of 139 patients were included in this study, the mean age of patients was $33.26 \pm 19$ years. Out of 139 patients, $40.3 \%$ were from rural areas, $60 \%$ were male and $44.6 \%$ study subjects were illiterate. Our main variables of interest were, first contact of health care provider with patients, door to first contact time(minutes), door to treatment time, presenting complaints of patients, investigations advised to patients, treatment given to patients and door to exit time (minutes). Analysis of these variables showed results as presented in table-I and II.

Table-I shows that maximum $75 \%$ of total study subjects received care by doctors with $25.9 \%$ complaints of Gastro-intestinal tract, and 50 (36\%) of patients included in this study were not advised any investigation, $33(24.3 \%$,) and $27(19.4 \%)$ were advised X-Ray/Ultrasound. 
Table-I: Pattern of Healthcare Providers, Presenting Complaints and Investigations advised, among patients attending Emergency Department.

\begin{tabular}{|c|c|c|c|}
\hline & Variable & $\begin{array}{c}\text { Freque } \\
\text { ncy }\end{array}$ & \begin{tabular}{|l|} 
Percent \\
age $(\%)$ \\
\end{tabular} \\
\hline \multirow{5}{*}{$\begin{array}{l}\text { Health care } \\
\text { provider }\end{array}$} & Doctor & 105 & 75.5 \\
\hline & Dispenser & 23 & 16.5 \\
\hline & Nurse & 9 & 6.5 \\
\hline & OT boy & 2 & 1.4 \\
\hline & Total & 139 & 100 \\
\hline \multirow{11}{*}{$\begin{array}{l}\text { Presenting } \\
\text { Complaints } \\
\text { of Study } \\
\text { subjects }\end{array}$} & GIT & 36 & 25.9 \\
\hline & RTA & 25 & 18 \\
\hline & $\begin{array}{l}\text { Respiratory } \\
\text { infection }\end{array}$ & 14 & 10.1 \\
\hline & CVS & 12 & 8.6 \\
\hline & Dermatology & 12 & 8.6 \\
\hline & CNS & 12 & 8.6 \\
\hline & Fever & 8 & 5.8 \\
\hline & Musculoskeletal & 8 & 5.8 \\
\hline & Genitourinary & 7 & 5 \\
\hline & Eye/ENT/Dental & 5 & 3.6 \\
\hline & Total & 139 & 100 \\
\hline \multirow{7}{*}{$\begin{array}{l}\text { Investigations } \\
\text { advised to } \\
\text { study } \\
\text { subjects. }\end{array}$} & None & 50 & 36 \\
\hline & $\begin{array}{l}\text { X-Ray/ } \\
\text { Ultrasound }\end{array}$ & 27 & 19.4 \\
\hline & Blood pressure & 33 & 24.3 \\
\hline & ECG & 12 & 8.6 \\
\hline & $\begin{array}{l}\text { Lab. } \\
\text { Investigations }\end{array}$ & 9 & 6.5 \\
\hline & BSR & 8 & 5.8 \\
\hline & Total & 139 & 100 \\
\hline \multirow{8}{*}{$\begin{array}{l}\text { Treatment } \\
\text { given to study } \\
\text { subjects. }\end{array}$} & First Aid & 4 & 2.9 \\
\hline & Injection & 37 & 26.6 \\
\hline & Medication & 21 & 15.9 \\
\hline & Referral & 36 & 25.9 \\
\hline & $\begin{array}{l}\text { First Aid + } \\
\text { Injection }\end{array}$ & 7 & 5 \\
\hline & $\begin{array}{l}\text { Injection+Medic } \\
\text { ation }\end{array}$ & 26 & 18.7 \\
\hline & $\begin{array}{l}\text { First Aid + } \\
\text { Injection + } \\
\text { Medication }\end{array}$ & 8 & 5.8 \\
\hline & Total & 139 & 100 \\
\hline
\end{tabular}

Table-II: Description of Time to $1^{\text {st }}$ contact, time to treatment and Time to Exit

\begin{tabular}{|c|c|c|c|c|}
\hline \multicolumn{2}{|c|}{ Variable } & \multirow{2}{*}{$\begin{array}{r}\begin{array}{r}\text { Frequ } \\
\text { ency }\end{array} \\
67 \\
\end{array}$} & \multirow{2}{*}{$\begin{array}{c}\begin{array}{c}\text { Perce } \\
\text { ntage }\end{array} \\
48.2 \\
\end{array}$} & $\begin{array}{c}\text { Mean } \\
\pm \text { SD } \\
\end{array}$ \\
\hline \multirow{6}{*}{$\begin{array}{l}\text { Door to first } \\
\text { contact time } \\
\text { (minutes). }\end{array}$} & $1-4$ & & & \multirow{6}{*}{$\begin{array}{c}5.6 \\
\pm 4 . \\
7 \\
\end{array}$} \\
\hline & $5-8$ & 48 & 34.5 & \\
\hline & $9-12$ & 15 & 10.8 & \\
\hline & $13-16$ & 6 & 4.3 & \\
\hline & More than 16 & 3 & 2.2 & \\
\hline & Total & 139 & 100 & \\
\hline \multirow{7}{*}{$\begin{array}{l}\text { Door to } \\
\text { treatment } \\
\text { time } \\
\text { (minutes). }\end{array}$} & $1-5$ & 20 & 14.4 & \multirow{7}{*}{$\begin{array}{c}12 \\
1 \pm 6 \\
.8\end{array}$} \\
\hline & $6-10$ & 49 & 35.3 & \\
\hline & $11-15$ & 41 & 29.5 & \\
\hline & $16-20$ & 16 & 11.5 & \\
\hline & $21-25$ & 8 & 5.8 & \\
\hline & More than 25 & 5 & 3.5 & \\
\hline & Total & 139 & 100 & \\
\hline \multirow{8}{*}{$\begin{array}{l}\text { Door to exit } \\
\text { time (Total } \\
\text { Time) } \\
\text { (minutes). }\end{array}$} & $0-10$ & 9 & 6.5 & \multirow{8}{*}{$\begin{array}{c}30 \pm \\
23 \\
7\end{array}$} \\
\hline & $11-20$ & 50 & 35.9 & \\
\hline & $21-30$ & 39 & 28.1 & \\
\hline & $31-40$ & 23 & 16.6 & \\
\hline & $41-50$ & 6 & 4.3 & \\
\hline & $51-60$ & 2 & 1.4 & \\
\hline & More than 60 & 10 & 7.2 & \\
\hline & Total & 139 & 100 & \\
\hline
\end{tabular}

Table-II shows that first contact time of $48.2 \%$ study subjects was below 5 minutes, while $35.3 \%$ patients were treated within 6-10 minutes \& only $3.5 \%$ treated after 25 minutes. Table-II also showing that mean door to treatment time was $12.1 \pm 6.8$ minutes, and $35.9 \%$ of study subjects were treated between 11-20 minutes and got exit from emergency department.

Table-III: Door to Exit time (Total Time) vs Presenting Complaints.

\begin{tabular}{|l|c|c|c|c|}
\hline \multirow{2}{*}{$\begin{array}{l}\text { Presenting } \\
\text { Complaints }\end{array}$} & \multicolumn{4}{|c|}{ Door to Exit Time ( minutes ) } \\
\cline { 2 - 5 } GIT & $\mathbf{0 - 3 0}$ & $\mathbf{3 1 - 6 0}$ & More than 60 & Total \\
\hline RTA/Surgery & $26(72.23 \%)$ & $8(22.22 \%)$ & $2(5.55 \%)$ & $36(100 \%)$ \\
\hline Respiratory & $12(48 \%)$ & $9(36 \%)$ & $4(16 \%)$ & $25(100 \%)$ \\
\hline CVS & $12(85.71 \%)$ & $0(0 \%)$ & $2(14.29 \%)$ & $14(100 \%)$ \\
\hline Dermatology & $8(66.67 \%)$ & $3(25 \%)$ & $1(8.33 \%)$ & $12(100 \%)$ \\
\hline CNS & $11(91.67 \%)$ & $1(8.33 \%)$ & $0(0 \%)$ & $12(100 \%)$ \\
\hline Fever & $9(75 \%)$ & $3(25 \%)$ & $0(0 \%)$ & $12(100 \%)$ \\
\hline Musculoskeletal & $6(75 \%)$ & $2(25 \%)$ & $0(0 \%)$ & $8(100 \%)$ \\
\hline Genitourinary & $7(87.5 \%)$ & $1(12.5 \%)$ & $0(0 \%)$ & $8(100 \%)$ \\
\hline Eye/ENT/Dental & $3(42.86 \%)$ & $4(57.14 \%)$ & $0(0 \%)$ & $7(100 \%)$ \\
\hline Total & $4(80 \%)$ & $0(0 \%)$ & $1(20 \%)$ & $5(100 \%)$ \\
\hline
\end{tabular}


Table-III shows that $70.5 \%$ of total study subjects were treated and discharged within 1-30 minutes from emergency department, and most of them were having GIT complaints.

\section{Discussion}

Present study concluded that age of all 139 study subjects ranges between 8 months to 85 years, among which $34.5 \%$ were under 25 years of age while $65.5 \%$ were above 25 years. Results of our study could be compared with an article from New York that showed maximum number $39.6 \%$ patients were between ages 18-44 years. ${ }^{11}$ Present study revealed that $67(48.2 \%)$ of total study subjects got their first contact with health care provider within 1-4 minutes, 48 (34.5\%) within 58 minutes, 15 (10.8\%) within 9-12 minutes while only $3(2.2 \%)$ of patients had to wait for more than 60 minutes. Results of our study correlates with a study conducted in Ethopia for delayed presentation and care of the patients to rural areas. ${ }^{12}$ Another survey conducted by Ibtisam and Sana in Health and Quality of Life Journal correlates with our study results. ${ }^{13}$

Among the subjects under study 49 (35.7\%) received treatment within 6-10 minutes, 41 (29.5\%) within $11-15$ minutes, and only 13 (9.3\%) after 20 minutes. There was a definite increased chance of being attended late, results are comparable with a study conducted by Nielsen R, Perez N, Petersen P and Biering K in 2014. ${ }^{14}$ In our study, $36(25.9 \%$ of total study subjects presented with complaints of gastro-intestinal tract, with RTA were $18 \%, 10.1 \%$ were with respiratory complaints and $8.6 \%$ were having dermatological problems. Present study results are not comparable with that, which was conducted in New York, showing that 7\% were having complaints of GIT and 5\% were with dermatological problems. ${ }^{15}$ It has also been noticed in previous studies that almost $50 \%$ of emergency visits are of non-emergency type. ${ }^{4,5}$ This huge patient census who presented with variable complaints dictates the necessity of distribution of patients according to their symptoms severity. This problem can be very finely resolved by the establishment of the Emergency Triage system, it is in working in some of the developed countries, that has eased the total burdon of emergency departments. Triage system considers the patient requirements of health care provision and accordingly it allocates the important finite sources available to the accident and Emergency department by categorization to those who needs it the most. ${ }^{4}$

Current study showed that total time spent by study subjects in emergency department; 59 (42.4\%) spend less than 20 minutes, $62(44.7 \%)$ spend $21-40$ minutes, $8(5.7 \%) 41-60$ minutes and $10(7.2 \%)$ spend more than one hour. These results are in contrast with a study conducted by El Sayed M, ElEid G, Saliba M et al, done in Baltimore which shows that $68.1 \%$ patients were discharged after 30 minutes of their arrival and $31.9 \%$ spent 30 or less than 30 minutes in emergency department. ${ }^{16}$

Importantly, three key components could be applied to improve the efficacy of emergency services are, Planning, Management and Operation. Hospital administration and staff workers should do Planning and even Pre-planning to organize an effective system and to accomplish their duties. After planning, good management plays its role, as fifty percent of the efficiency is management system issue. Five aspects of emergency department that seriously affects the speed and efficiency of patient outflow: paramedics and clerical staff, Lab and XRay turnaround, chart flow system within departments, speed with which staff works, and the time it takes to get a patient being admitted and treated. Remaining 50\% of efficiency depends upon on-duty emergency physicians that day, how they utilize and work within emergency department. Effective Operation system requires efficient number of doctors and staff members should be in place not documentarily but in practical with necessary medicines \& equipments also. All necessary investigations should also be held properly and in time. ${ }^{8}$

To improve emergency services efficiency, decisiveness is key element in managing patient flow. So, all the physicians who are working in emergency should be decisive although it takes some times to be experienced but they can cope up by adopting some strategies to be a faster in their actions. These strategies could be practiced by physicians at all levels of experience like; ${ }^{8}$ the physician should be $100 \%$ focused, anticipate phone calls, be flexible, delegate as much as possible, avoid 
ordering any un-necessary tests, keep the big picture in mind because you are running whole department, keep a log and take short breaks \& adequate nutrition etc. ${ }^{7}$ This problem can be very finely resolved by the establishment of the Emergency Triage system, it is in working in some of the developed countries, that has eased the total burden of emergency departments. Triage system considers the patient requirements of health care provision and accordingly it allocates the important finite sources available to the accident and Emergency department by categorization to those who needs it the most. ${ }^{4}$ Outcome of this wellestablished Emergency Triage System is the shortening of length of stay (LOS) in emergency department and in return we can also predict the inpatients LOS. This system can provide most efficient and rapid emergency services to severe ones. This triage system is commonly in use in all developed countries but not well established in developing countries. The situation of emergency services in Pakistan requires a lot of improvements, basic health care facilities are deficient and funding status by government is also poor. Most of our hospitals and their emergency departments are working by the rule of "first come-first served". Drawbacks of this system are mainly that we can't assess the severity of the patients and their treatment needs, resulting ignorance of the serious patients, they have to wait for their turn. ${ }^{4}$

\section{Conclusion}

This study showed that almost half of the patients received treatment within four minutes while few of the patients have to wait for upto twenty five minutes to get healthcare, which is quite a long time as for as emergency healthcare services is concerned., additionally only half of the patients were received by doctors. For last few years, instead of high rise in volume and complexity of patients presenting to emergency departments, government hospitals have become successful in reducing the patient's average length of stay in emergency departments.

Well-communicated and united approach to emergency departments with early decision making by senior staff, patient emergency care planning and decisiveness, commitment to remove barriers between emergency department and in-patient wards, helps to improve the efficacy and efficiency of emergency services of an institution or organization.

\section{Author Contribution}

SW: Conception of work, design of work and revising. NK: Design of work, Acquisition and analysis of data and drafting. MA: Interpretation of data and revising.

All authors critically revised and approve its final version.

\section{Conflict of interest: None \\ Resources of funding: Self}

\section{References}

1. Baker L, Baker L. Excess cost of emergency department visits for non urgent care. Health Affairs 1994; 13(5): 162-171.

2. Doobinin K, Heidt-Davis P, Gross T, Isaacman D. Non urgent pediatric emergency department visits: Care seeking behavior and parental knowledge of insurance. Pediatric emergency care 2003; 19(1): 10-14.

3. A. Sharon. Shortening Emergency Department Waiting Times Through Evidenced-Based Practice. Locatible Health Tech Hub. Available online; http://www.acep.org/clinical. Locatible Health Tech Hub. 128-133.

4. Noorani M, Khaliq M, Shoaib M. Time intervals and associated factors of emergency treatment: first insight into Pakistani system. International archives of Medicine 2014; 7(1): 41.

5. Smart America. Smart Emergency Response System (SERS) [Internet]. Smartamerica.org. Available from: http://smartamerica.org/teams/smart-emergency-responsesystem-sers/

6. The Five Giants by Nicholas Timmins - Paperback Revised Edition | Harper Collins. Available from: https ://www. Harpercollins .co.uk/9780007102648/the-five-giants

7. Abel-Smith B. A history of the nursing profession. 1st ed. London [ u.a.]: Heinemann; 1970

8. Emergency medical service. Available from: https://www. ems.gov/ whatisems.html

9. "British Red Cross Ambulance Support". British Red Cross. Retrieved. 2017-07-02.

10. Mason, Suzanne; Knowles, Emma; Boyle, Adrian. Exit block in emergency department: a rapid evidence review. Emergency Medicine Journal 2017; 34(1): 46-51. PMID 27789568

11. Raven M, Lowe R, Maselli J, Hsia R. Comparison of Presenting Complaints vs Discharge Diagnosis for Identifying "Nonemergency" Emergency Department Visits. JAMA 2013; 309(11): 1145

12. Cambanis A, Yassin M, Ramsay A, Bertel Squire S, Arbide I, Cuevas L. Rural poverty and delayed presentation to tuberculosis services in Ethiopia. 2017.

13. Sabbah I, Drouby N, Sabbah S, Retel-Reude N, Mercier M. Quality of Life in rural and urban populations in Lebanon using SF-36 Health Survey. Health and Quality Of Life Outcomes 2003; 1(1): 30 .

14. Nielsen R, Perez N, Petersen P, Biering K. Assessing time to treatment and patient inflow in a Danish emergency department: a cohort study using data from electronic emergency screen boards. BMC Research Notes 2014; 7(1): 690.

15. Raven M, Lowe R, Maselli J, Hsia R. Comparison of Presenting Complaint vs Discharge Diagnosis for identifying "Nonemergency" Emergency Department Visits. JAMA 2013; 309(12): 1146.

16. El Sayed M, El-Eid G, Saliba M. Improving Emergency Department Door to Doctor Time and Process Reliability. Medicine 2015; 94(42): 1679. 